\title{
Intrigues and Challenges Associated with COVID-19 Pandemic in Nigeria
}

\author{
Kabiru Olusegun Akinyemi*, Christopher Oladimeji Fakorede, A. Abdul Azeez Anjorin, \\ Rebecca Omotoyosi Abegunrin, Olabisi Adunmo, Samuel Oluwasegun Ajoseh, \\ Funmilayo Monisola Akinkunmi
}

Department of Microbiology, Lagos State University, Ojo, Lagos, Nigeria

Email: ^akinyemiko@yahoo.com

How to cite this paper: Akinyemi, K.O., Fakorede, C.O., Anjorin, A.A.A., Abegunrin, R.O., Adunmo, O., Ajoseh, S.O. and Akinkunmi, F.M. (2020) Intrigues and Challenges Associated with COVID-19 Pandemic in Nigeria. Health, 12, 954-971.

https://doi.org/10.4236/health.2020.128072

Received: May 15, 2020

Accepted: August 14, 2020

Published: August 17, 2020

Copyright $\odot 2020$ by author(s) and Scientific Research Publishing Inc. This work is licensed under the Creative Commons Attribution International License (CC BY 4.0).

http://creativecommons.org/licenses/by/4.0/

\begin{abstract}
Coronavirus disease 2019 (COVID-19) pandemic has emerged as a global health crisis, with 3,855,788 infected persons and 256,862 deaths worldwide as of May 9, 2020. In Nigeria, the first case of the pandemic was reported by the Nigerian Centre for Disease Control on February 27, 2020. Between the dates when the index case was reported and May 9, 2020, the nation has recorded a total of 4151 confirmed COVID-19 cases from 25,951 samples screened and $745(18 \%)$ cases discharged with 128 deaths indicating a case fatality rate of $3.1 \%$. Thirty-four (34) States and the Federal Capital Territory have recorded coronavirus disease. The most affected States in Nigeria is Lagos (epicentre of COVID-19) with 1764 cases, followed by 576 cases in Kano states and only one COVID-19 case in Anambra State 42 days since the last report of index case. Demographically, a total of 2828 male subjects have been infected representing $68 \%$ and 1323 female subjects representing $32 \%$. The age group $31-40$ years is mostly affected accounting for $24 \%$. The number of people with travel history is $210(5 \%), 947$ (23\%) contacts, $2618(63 \%)$ without epidemiological link and 376 (9\%) with an incomplete information. Nigeria is currently witnessing community transmission of COVID-19. Some observed issues aiding community transmission of COVID-19 in Nigeria are: the distrust of some Nigeria citizens towards government on COVID-19 management, poverty, religious beliefs, ignorance on face mask sharing, low level of informed populace, misconceptions, stigmatization of infected individuals, poor health facilities, inadequate testing Centre, shortage of health workers, poor treatment among others. Effective people's health preventive behaviour and community-based health policy and strategies to mitigate these challenges are therein suggested.
\end{abstract}

\section{Keywords}

Coronavirus, COVID-19, SARS-CoV-2, Challenges, Health, Nigeria 


\section{Introduction}

The coronavirus disease (COVID-19) caused by Corona virus, belongs to a family of RNA viruses that manifest various symptoms such as fever, breathing difficulty, sore throat, sneezing, dry or productive cough, general weakness, pain and other mild respiratory disease in human [1] [2] [3]. These viruses are common in animals worldwide, but very few cases have been known to affect humans [4]. The World Health Organization (WHO) used the term 2019 novel coronavirus to refer to a coronavirus that affects the lower respiratory tract of patients with pneumonia-like disease that was identified and first documented in Wuhan, Hubei Province in China in December 2019 [5] [6] [7]. The WHO officially named the 2019 novel coronavirus as (COVID-19), since the organization felt calling the virus Wuhan coronavirus was discriminatory (WHO, 2020), while the current reference name for the virus is severe acute respiratory syndrome coronavirus 2 (SARS-CoV-2) [4]. In December 2019, some patients with pneumonia-like symptom of unknown origin were linked to a local Huanan South China Seafood Market in Wuhan, Hubei Province, China. In order to conduct an epidemiological investigation and to determine the etiological agent, the Chinese Center for Disease Control and Prevention (China CDC) dispatched a team of its health authorities to respond to the outbreak. A closure notice was served to the market and a day after the market was shut down and fumigated [1] [4] [8]. The WHO affirmed that the outbreak of the coronavirus disease epidemic at that time was associated with the Huanan South China Seafood Marketplace, however, no specific animal was linked to the outbreak [9]. Adhikari et al. [4] reported that the spread of the virus throughout China during the Chinese New Year, was attributed to a high level of human of movement among Chinese people during that festive period. The first genome of COVID-19 was published on 10 January 2020 by the research team led by Prof. Yong-Zhen Zhang [10]. So far, there are over 1000 COVID-19 genomes that have been published worldwide [11], including the first whole genome sequencing of COVID-19 in Africa from the index case in Nigeria. These sequencing has resulted in the identification of different strains of SARS-CoV-2 in circulation. However, while it is still too early to infer susceptible populations, it has been documented that observation from the early disease patterns demonstrated pandemic trend similar to Severe Acute Respiratory Syndrome (SARS) and Middle East respiratory syndrome (MERS) coronaviruses [4]. Demographics of the pandemic seem to be associated with age, biological sex, and other underlying health conditions that may serve as catalyst to the coronavirus disease [12]. COVID-19 was declared Pandemic (Public Health Emergency of International Concern) by the world health organization by early March, 2020 [13]. Barely two months later, 212 countries and territories had been affected globally including Nigeria. Some of these countries have witnessed plateau of the pandemic cases and new cases continue to decline. But most African countries are yet to reach the peak of the pandemic as cases of community transmission are on daily increase. 


\section{Virology and Pathogenesis}

Severe acute respiratory syndrome coronavirus 2 (SARS-CoV-2) belongs to the family Coronaviridae, genus Betacoronavirus causing coronavirus disease 2019 (COVID-19) [14] [15]. They are spherical or pleomorphic, enveloped single-stranded RNA viruses that is 29,811 nucleotides long, broken down into 8903 (29.86\%) adenosines, 5482 (18.39\%) cytosine's, 5852 (19.63\%) guanines, and 9574 (32.12\%) thymine's [14] and are covered with club shaped glycoprotein [16]. All human CoVs including SARS-CoV-2 are zoonotic in nature and several human CoVs have originated from bats, including the SARS- and MERS-CoVs [17] and are known to cause varying symptoms that ranges from those similar to the common cold to more severe respiratory, enteric, hepatic, and neurological symptoms [8] [18], WHO, $2020 \mathrm{C}$ ). Presently, there are four sub-types of coronavirus, these are alpha, beta, gamma and delta corona virus. Each sub type has many serotypes. Some of them affect human while others affect animals such as pigs, birds, cats, mice and dogs [16]. Seven known coronaviruses in humans have been identified: HCoV-229E, HCoV-OC43, HCoV-NL63, HCoV-HKU1, MERS-CoV, SARS-CoV and most recent SARS-CoV-2 [19] [20] [21] [22]. The estimated incubation period of COVID-19 ranges from one to 14 days. Studies have revealed $97.5 \%$ of people with SARS-CoV-2 infection usually manifest COVID-19 compatible symptoms within 11.5 days [1]. Although, comparative genome studies of SARS-CoV-2 reported to have originated in bats and that pangolins (Manis javanica) were an intermediate mammalian host [17] [23], however, its true origin continues to generate controversies among countries.

In a recent study conducted by Ren et al., [24] and Roujian et al., [25], whole genome sequence results of SARS-CoV-2 showed 79.0\% nucleotide identity with the sequence of SARS-CoV (GenBank NC_004718) and 51.8\% identity with the sequence of MERS-CoV (GenBank NC_019843) revealing that SARS-CoV-2 was more distant from strain from SARS-CoV. However, the virus is phylogenetically closest to two bat-derived SARS-like coronaviruses-bat-SL-CoVZC45 (with $87.9 \%$ sequence identity) and bat-SL-CoVZXC21 (with $87.2 \%$ sequence identity) as reported in the study by Roujian et al., [25], and Ren et al., [24] but is in a separate clade. Furthermore, these viruses have a single intact open reading frame gene ORF3 different from that of SARS-CoVs and secreted encoded protein ORF8, as a further indicator of bat-origin CoVs. However, the amino acid sequence of the tentative receptor-binding domain was reported to resemble that of SARS-CoV, indicating that these viruses might use the same receptor.

The COVID-19 interact with the Renin-angiotensin-aldosterone-system (RAAS) through angiotensin-converting enzyme 2 (ACE2), an enzyme that physiologically counters RAAS activation but also functions as a receptor for SARS viruses [26]. Studies have shown that COVID-19 S-protein supported strong interaction with human ACE2 molecules despite the dissimilarity of its sequence with that of SARS-CoV [25] [27]. The spike C-terminal domain of the SARS-CoV2 has much stronger affinity for ACE2, having several atomic points of contact [17] 
[23]. The interaction between the SARS viruses and ACE2 has been proposed as a potential factor in their infectivity [28] [29]. Substitution of amino acid sequence at positions 723 and 1010 involving the replacement of glycine amino acid with serine and isoleucine with proline respectively in the ORF1ab encoded 2 (nsp2) and nsp3 has been reported to have been responsible for the changes observed in the SARS-CoV-2 [30]. However, the $100 \%$ similarity in the amino acid sequence of nsp7 and E-protein of SARS-CoV-2 found in Bat-SARS-Cov-ZC45 is believed not be a natural mutation, except it is genetically engineered through recombinant technology. Theory has been circulating that the coronavirus at the root of COVID-19 pandemic originated from the research laboratory. However, whether the unusual $100 \%$ similarity in the amino acid sequence of nsp7 and E-protein of SARS-CoV-2 found in Bat-SARS-Cov-ZC45 is a natural mutation or conjured and/or escape from laboratory, scientists all over the world are working hard to unravel the controversy.

\section{Viral Shedding and Transmission}

The European Centre for disease prevention and control [1] reported that during the course of the infection, the virus has been identified in respiratory tract specimens 1 - 2 days before the onset of symptoms which can persist for up to eight days in moderate cases and for longer periods in more severe cases, peak of the infection is expected in the second week. The viral load close to symptom onset suggests that SARS-CoV-2 can be easily transmissible at an early stage of infection according to the Centre. The detection of Viral RNA in feaces from day 5 after symptom onset, up to 4 to 5 weeks in moderate cases, and more than one month after infection in paediatric patients has been reported [1]. While whole blood, serum, saliva and urine have also shown the presence of viral RNA. Prolonged viral RNA shedding has been reported from nasopharyngeal swabs for up to 37 days among adult patients according to ECDPC [1]. In a recently study by Li et al., [31], the novel coronavirus can persist in men's semen even after they have begun to recover, a finding that raises the possibility of transmission of COVID -19 sexually. Six (6) out of the 38 (15.8\%) of the total participant whose semen were screened had results positive for SARS-CoV-2. This includes those still at the acute stage of the disease as well as those recovering from the disease.

COVID-19 is primarily transmitted from symptomatic people to others who are in close contact through respiratory droplets, by direct contact with infected individuals, or by contact with contaminated objects and surfaces [18] [32] [33]. It had been reported shedding of the COVID-19 virus is prominent in upper respiratory tract early in the stage of the disease [17] [34], thus, making the disease more contagious around the time of symptom onset than later stage of disease [32] [35].

It has been documented that pre-symptomatic transmission (the time when the person becoming infected and symptom onset occurs) during the incubation period for COVID-19, which may take an average of 5 - 6 days and may last up to 14 days [18]. During this period, some infected persons can be contagious. 
Therefore, transmission from a pre-symptomatic case can occur before symptom onset [36] [37] and that some people can test positive for COVID-19 from 1-3 days before symptoms development [18]. Thus, raising the possibility of COVID-19 transmission by infected persons prior to development of significant symptoms.

There are few reports of laboratory-confirmed cases that are truly asymptomatic, and to date, there has been no documented asymptomatic transmission. The WHO defines asymptomatic transmission an asymptomatic laboratory-confirmed case as a person infected with COVID-19 who does not develop symptoms [18]. Currently, an index case of COVID-19 in Benue State, Nigeria has not developed any symptom of coronavirus disease after 43 days in an isolation Centre without medication (http://www.vanguardngr.com/, theeditor@punchng.com, https://ait.live).

\section{Epidemiology of COVID-19}

Since the $31^{\text {st }}$ of December 2019 when the outbreak was announced to $7^{\text {th }}$ May 2020 between 6:00 and 10:00 CET (Central European time), three million, seven hundred and thirteen thousand seven hundred and ninety six $(3,713,796)$ cases of COVID-19 (in accordance with the applied case definitions and testing strategies in the affected countries) have been reported worldwide, including two hundred twenty sixty three thousand and two hundred and eighty eight (263 288) deaths [38]. Some countries across the continents that mostly reported cases and death from COVID-19 as at May 7, 2020 are as shown in Table 1. For example, in the USA $1,228,603$ cases with 73,431 deaths recorded were recorded, Italy recorded 214,457 cases with 29,684 deaths and the cases of COVID-19 in Turkey were 131,744 with 3584 deaths. Other countries that recorded high cases and death from this disease are as shown in Table 1.

\subsection{Africa updates on COVID-19}

The first COVID-19 case in Africa was reported in Egypt on the $14^{\text {th }}$ of February, 2020 followed by Algeria on the $25^{\text {th }}$ of February, Algeria is one of the 13 countries which WHO has identified as a top priority for preparedness measures due to their direct link or high volume of travel to China. Other African countries started reporting their index cases afterwards. Nigeria is the first sub-Saharan Africa country to report the COVID-19 confirmed case. Most of the identified imported cases in Africa arrived from Europe and the United States rather than from China [39]. Africa recorded her first fatality of COVID-19 in Burkina Faso on $18^{\text {th }}$ March 2020, a female patient aged 62 years old, with underlying diabetes condition [40]. The distribution of COVID -19 disease in Africa as reported by the World Health Organization regional office Africa from the $14^{\text {th }}$ February of the index case to 6 May 2020 is shown in Figure 1.

Testing for COVID-19 has been a challenge in the continent. In a tweet by the African Centre for Disease Control on the $4^{\text {th }}$ of May via its Twitter handle @AfricaCDC the Centre's Director General said the collapse of global coopera- 
tion and failure of international solidarity have shoved Africa out of the global coronavirus diagnostic market. He however, decried the low testing rate for COVID-19 in Africa, warning that no country could securely eliminate the pandemic without a synergy from other countries [41].

\subsection{Corona Virus Disease (COVID-I9) Pandemic in Nigeria}

The index case of the coronavirus disease (COVID-19) was reported in Nigeria

Table 1. Outbreak in accordance with the applied case definitions and testing strategies in the Affected countries from 31 December to 7 May, 2020 between 6:00 and 10:00 CET.

\begin{tabular}{|c|c|c|c|c|c|c|}
\hline \multirow{2}{*}{$\begin{array}{l}\text { Continent } \\
\text { AFRICA }\end{array}$} & \multirow{2}{*}{$\begin{array}{c}\begin{array}{c}\text { Total } \\
\text { number of } \\
\text { case }\end{array} \\
51,677\end{array}$} & \multirow{2}{*}{$\begin{array}{c}\begin{array}{c}\text { Total } \\
\text { number of } \\
\text { deaths }\end{array} \\
2011\end{array}$} & \multicolumn{2}{|c|}{$\begin{array}{l}\text { Five countries } \\
\text { reporting most cases }\end{array}$} & \multicolumn{2}{|c|}{$\begin{array}{l}\text { Five countries } \\
\text { reporting the most deaths }\end{array}$} \\
\hline & & & South Africa & 7808 & Algeria & 476 \\
\hline & & & Egypt & 7580 & Egypt & 469 \\
\hline & & & Morocco & 5408 & Morocco & 183 \\
\hline & & & Algeria & 4997 & South Africa & 153 \\
\hline & & & Nigeria & 3145 & Cameroon & 108 \\
\hline \multirow[t]{5}{*}{ AMERICA } & $1,595,437$ & 94,122 & USA & $1,228,603$ & USA & 73,431 \\
\hline & & & Brazil & 125,218 & Brazil & 8536 \\
\hline & & & Canada & 63,496 & Canada & 4232 \\
\hline & & & Peru & 54,817 & Mexico & 2704 \\
\hline & & & Ecuador & 29,420 & Ecuador & 1618 \\
\hline \multirow[t]{5}{*}{ ASIA } & 597,979 & 20,730 & Turkey & 131,744 & Iran & 6418 \\
\hline & & & Iran & 101,650 & China & 4637 \\
\hline & & & China & 83,970 & Turkey & 3584 \\
\hline & & & India & 52,952 & India & 1783 \\
\hline & & & Saudi Arabia & 31,938 & Indonesia & 895 \\
\hline \multirow[t]{5}{*}{ EUROPE } & $1,459,723$ & 146,293 & Spain & 220,325 & United Kingdom & 30,076 \\
\hline & & & Italy & 214,457 & Italy & 29,684 \\
\hline & & & United kingdom & 201,201 & Spain & 25,857 \\
\hline & & & Germany & 166,091 & France & 25,809 \\
\hline & & & Russia & 165,929 & Belgium & 8339 \\
\hline \multirow[t]{6}{*}{ OCEANIA } & 8,284 & 125 & Australia & 6875 & Australia & 97 \\
\hline & & & New Zealand & 1139 & New Zealand & 21 \\
\hline & & & Guam & 151 & Guam & 5 \\
\hline & & & French & 60 & Northern & 2 \\
\hline & & & Polynesia & & Mariana Island & \\
\hline & & & Fiji & 18 & & \\
\hline OTHERS & 696 & 7 & \multicolumn{4}{|c|}{ Reported from an international conveyance in Japan. } \\
\hline
\end{tabular}

Source: ECDPC, Situation update worldwide, as of 7 May 2020. 


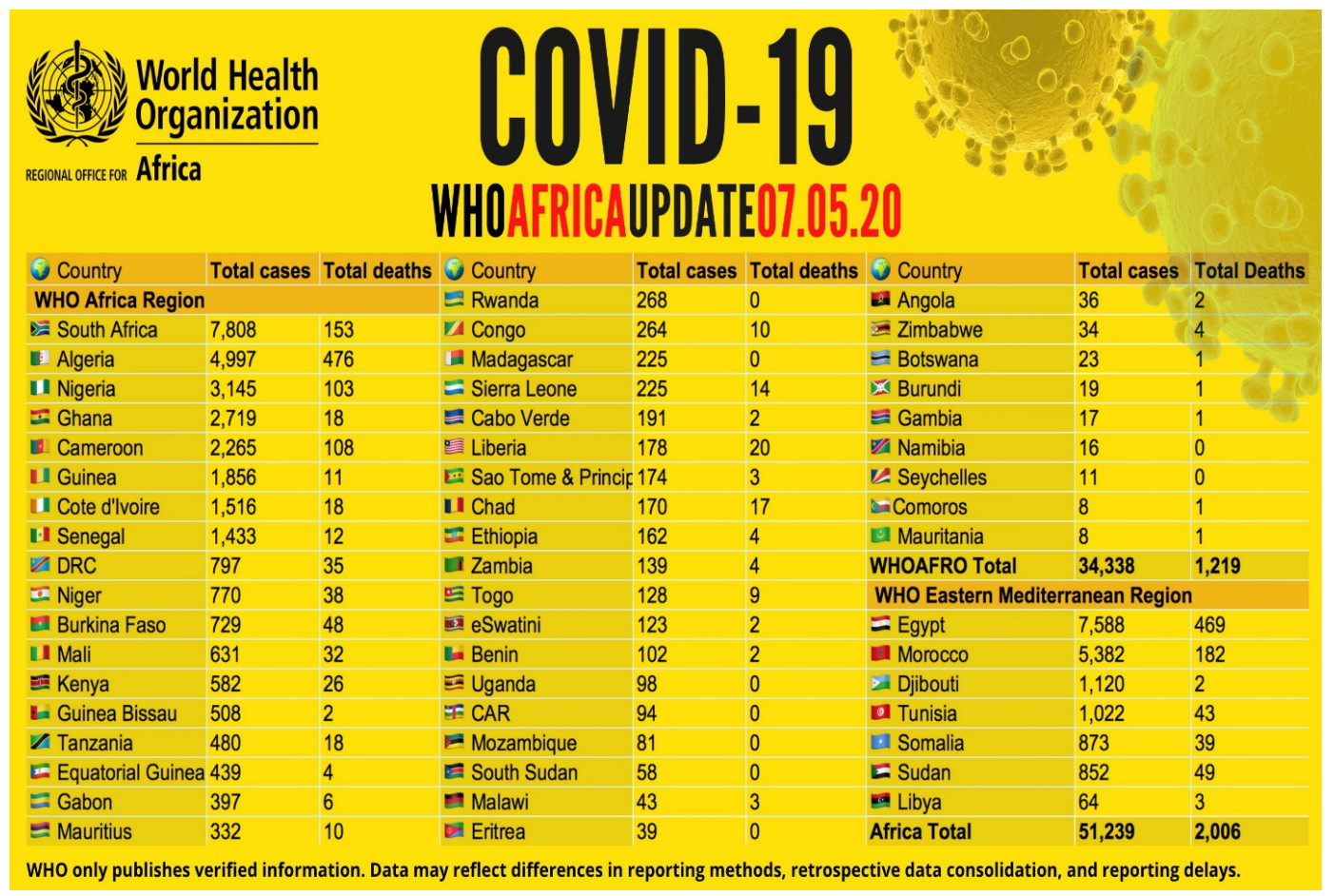

Figure 1. Distribution of confirmed COVID-19 cases in Africa as at 7 May 2020 according to World Health Organization regional office for Africa [41].

on the $27^{\text {th }}$ of February by the Nigeria Centre for disease control [42] and. Three days after the confirmation of Nigeria's first COVID-19 case, the genome sequencing results of the SARS-CoV-2 specimen were announced on March 1. African Center of Excellence for Genomics of Infectious Diseases (ACEGID) at Redeemer University was the first to analyze the sputum taken from an Italian consultant who entered Nigeria through Lagos Airport on February $27^{\text {th }}$. This is a clear indication that the continent's contribution to the growing global evidence to understand the virus's behavior outside China. In other to curb the spread of the disease, the Nigerian government announced a travel ban on 13 countries considered to be of high risk for COVD-19 with over 1000 confirmed cases on the $18^{\text {th }}$ of Mar 2020 with effect from $21^{\text {st }}$ of March, 2020. These countries include: China, Italy, USA, Iran, Germany, Spain, South Korea, Japan, UK, France, the Netherlands, Switzerland and Norway. However, the closure of land, sea and air borders was not effected until over three weeks of the recorded index case on the $27^{\text {th }}$ of February, unfortunately, the rush back from Europe to Nigeria and further intercity movement led to continuous increase in the number of imported COVID-19 pandemic cases and community transmission in the country, spreading across the states are quite worrisome [40]. Molecular laboratory with SARS-CoV-2 testing capacity are limited in Nigeria. The recent increase in the number of positive COVID-19 cases in Nigeria can be attributed to increase in the number of testing laboratories which rose from just 4 laboratories in February when the first index case was reported to 18 laboratories as at May 9, 2020. Efforts to expand testing laboratories to all the 36 states of the federation are 
ongoing, as the community spread of the pandemic is now a major concern in Nigeria. Although, the total lockdown of three States: Lagos with a population of about 20 million people, Ogun-a Gate-way state and neighboring state to Lagos, and the Federal Capital territory for 5 weeks between March $23^{\text {rd }}$ and May 4, 2020 was announced by Federal Government to mitigate the spread of the disease.

In order to continue to curb inter-State transfer of the COVID-19 pandemic, the Nigeria governor's forum announced inter-state lockdown, a move that was commendable. As part of curbing the spread of the pandemic the government declare closure of primary, secondary schools and tertiary institutions and reducing number of individuals at different gatherings to not more than 50 persons and later reduced to 20 and currently not more than 10 persons. The gathering includes places of worships, open markets, clubs, gym, Saloon, while civil servants on levels 1 to 15 specifically in Lagos State were asked to stay at home. The proactive measures put in place by government in this respect are commendable. However, the palliatives put in place as a stimulus for the less privilege persons witnessed a lot of criticisms by many Nigerans, as it was poorly coordinated, and mismanaged. The situation attracted revolts by many as lack of food would not let them stay at home. Reaction of these citizens prompted announcement of relaxation or ease of lockdown by Federal government from Monday the $4^{\text {th }}$ of May - a move that was considered disastrous amidst the rising number of community spread COVID-19 cases in Nigeria. Before the announcement of the lockdown on the $30^{\text {th }}$ of March, the country has only recorded 131 confirmed cases and 2 deaths, as of $4^{\text {th }}$ of May, 2020 when the lockdown was eased the number of confirmed cases has risen to 2558 with 87 deaths and by 9 May, 2020, the first case fatality was reported on the $23^{\text {rd }}$ of March 2020 [43]. As of 9 of May, Nigeria has recorded 4151 confirmed cases from 25,951 samples tested, 745 (18\%) recovered and discharged cases, and 128 deaths revealing a case fatality rate (CFR) of $3 \%$ across 34 of 36 States including Federal Capital Territory (44) as shown in Figure 2 and Table 2. The demographics of the coronavirus disease in Nigeria as reported by the NCDC revealed that of 4151 confirmed cases, 2828 (68\%) were male and 1323 (32\%) were female subjects. The most affected age group is between $31-40$ years (24\%), total number of people of interest are 9305 with 9291 (99.8\%-exceeded follow up). The number of people with travel history $-210(5 \%)$, contacts $-947(23 \%)$, without epidemiologic link -2618 (63\%), incomplete information -376 (9\%) [44]. The 63\% of the total confirmed cases without epidemiological link recorded is an indication of community spread of COVID-19 across the country.

The most affected State in Nigeria Lagos (epicentre of COVID-19 in Nigeria) with 1764 cases, followed by 576 cases in Kano states and only one COVID-19 case in Anambra State 42 days since the last report of index case (Table 2). As part of the measures to prevent the spread of this disease, Lagos State government took a step and directed its workers (public servants) on grade level 1 to 12 


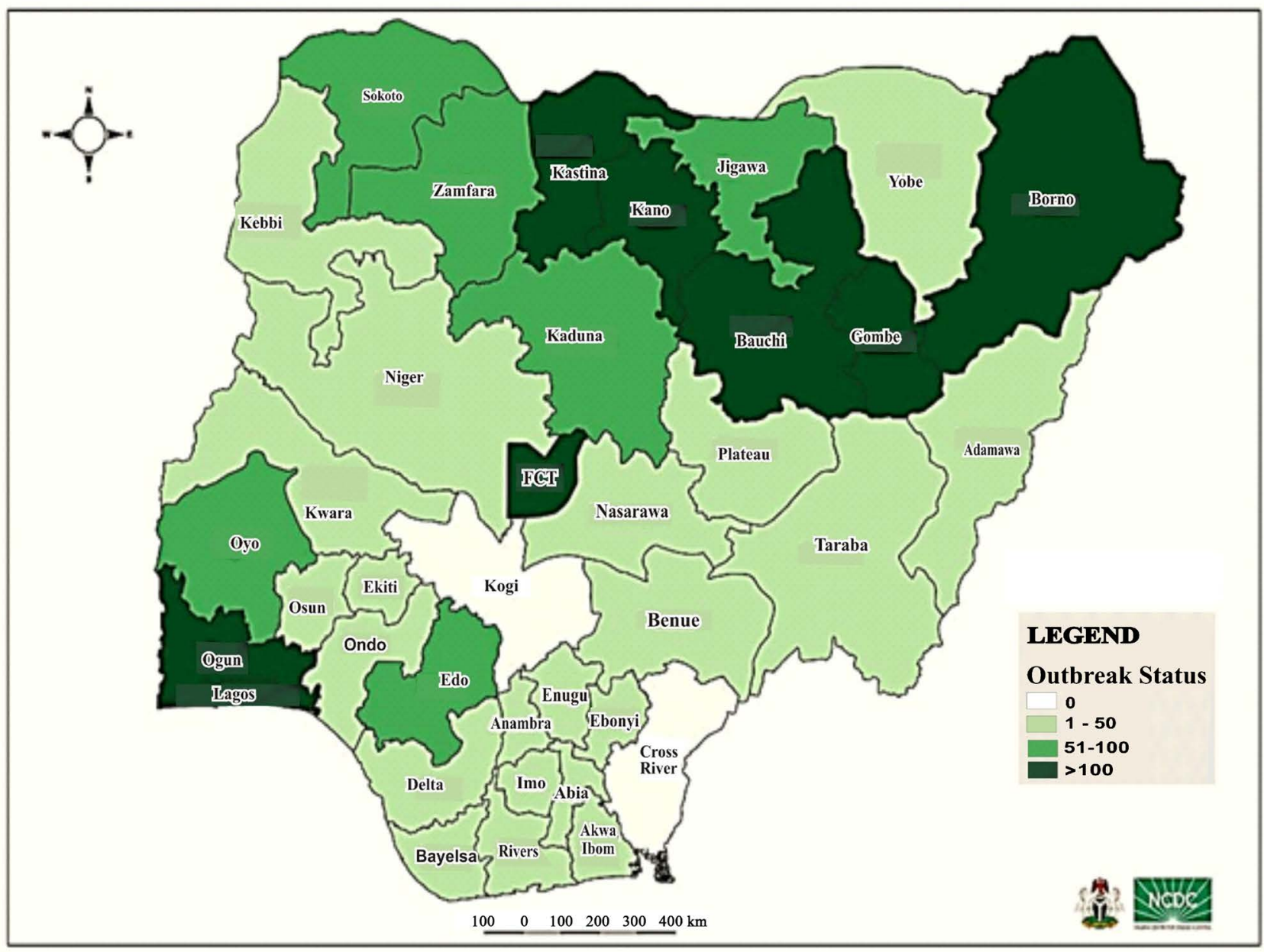

Figure 2. Map of Nigeria showing 34 states and FCT affected by COVID-19 [44].

to stay back at home since the beginning of the lockdown. This was extended to staff on grade level 13 to 15 with work from home order. Despite this measure, the usual Lagos traffic bottleneck has returned. The number of confirmed COVID-19 case is also fast rising in Northern Nigeria, the governors within that region agreed to send back all "Almajiris" (some northern youths mostly neglected children who at times attend Islamic and conventional schools and do beg for money on the streets for their livelihood) to their various States. A move by the northern governors to remove them from the streets in order to curtail the spread of the disease. On the $1^{\text {st }}$ of May, 2020 Punch newspaper reported that 16 Kano State "Almajiri” returnees tested positive to COVID-19 in Kaduna State, another 16 returnee from Kano to Jigawa State also tested positive, on the 7 of May, while 2 others returnee from Kano to Bauchi also tested positive an obvious fact that the decision by the northern governors came in a little too late. Increase in the confirmed cases of COVID-19 and community spread is expected in Nigeria without any doubt in the coming weeks or months. The rise in the confirmed case in Kano state is scary. The members of the presidential task force on COVID-19 that visited Kano State expressed concern about the high 
Table 2. States with reported laboratory-confirmed COVID-19 cases, recoveries, deaths and days since last reported case 9 May, 2020 [44].

\begin{tabular}{|c|c|c|c|c|c|c|c|c|}
\hline \multirow{2}{*}{ State } & \multicolumn{2}{|c|}{ Confirmed cases } & \multicolumn{2}{|c|}{ Discharged cases } & \multicolumn{2}{|l|}{ Deaths } & \multirow{2}{*}{$\begin{array}{l}\text { Total } \\
\text { active } \\
\text { cases }\end{array}$} & \multirow{2}{*}{$\begin{array}{l}\text { Days since } \\
\text { last reported } \\
\text { case }\end{array}$} \\
\hline & Cumulative & New & Cumulative & New & Cumulative & New & & \\
\hline LAGOS & 1764 & 97 & 448 & 0 & 33 & 0 & 1283 & 0 \\
\hline KANO & 576 & 29 & 30 & 10 & 18 & 0 & 528 & 0 \\
\hline FCT & 343 & 7 & 85 & 45 & 8 & 4 & 250 & 0 \\
\hline BAUCHI & 161 & 44 & 6 & 0 & 1 & 0 & 154 & 0 \\
\hline BORNO & 159 & 17 & 0 & 0 & 15 & 1 & 144 & 0 \\
\hline KATSINA & 156 & 19 & 9 & 0 & 9 & 1 & 138 & 0 \\
\hline OGUN & 115 & 2 & 33 & 5 & 4 & 0 & 78 & 0 \\
\hline GOMBE & 110 & 0 & 10 & 0 & 0 & 0 & 100 & 1 \\
\hline KADUNA & 98 & 3 & 14 & 0 & 3 & 1 & 81 & 0 \\
\hline SOKOTO & 96 & 3 & 10 & 6 & 9 & 0 & 77 & 0 \\
\hline JIGAWA & 83 & 0 & 0 & 0 & 1 & 0 & 82 & 2 \\
\hline EDO & 67 & 0 & 12 & 0 & 4 & 0 & 51 & 1 \\
\hline ZAMFARA & 65 & 0 & 0 & 0 & 3 & 0 & 62 & 2 \\
\hline OYO & 64 & 5 & 14 & 0 & 2 & 0 & 48 & 0 \\
\hline OSUN & 38 & 0 & 30 & 0 & 4 & 0 & 4 & 1 \\
\hline KWARA & 30 & 6 & 9 & 0 & 1 & 1 & 20 & 0 \\
\hline NASARAWA & 25 & 0 & 0 & 0 & 2 & 1 & 23 & 1 \\
\hline RIVERS & 21 & 0 & 4 & 0 & 2 & 0 & 15 & 1 \\
\hline KEBBI & 20 & 2 & 0 & 0 & 2 & 2 & 18 & 0 \\
\hline ADAMAWA & 17 & 2 & 0 & 0 & 0 & 0 & 17 & 0 \\
\hline AKWA IBOM & 17 & 0 & 10 & 0 & 2 & 0 & 5 & 2 \\
\hline DELTA & 17 & 0 & 3 & 0 & 3 & 0 & 11 & 8 \\
\hline PLATEAU & 17 & 2 & 1 & 0 & 0 & 0 & 16 & 0 \\
\hline ONDO & 15 & 0 & 6 & 0 & 0 & 0 & 9 & 1 \\
\hline TARABA & 15 & 0 & 0 & 0 & 0 & 0 & 15 & 4 \\
\hline EKITI & 13 & 1 & 4 & 0 & 1 & 0 & 8 & 0 \\
\hline YOBE & 13 & 0 & 0 & 0 & 1 & 0 & 12 & 8 \\
\hline ENUGU & 10 & 0 & 2 & 0 & 0 & 0 & 8 & 1 \\
\hline EBONYI & 7 & 0 & 0 & 0 & 0 & 0 & 7 & 1 \\
\hline NIGER & 6 & 0 & 2 & 0 & 0 & 0 & 4 & 2 \\
\hline BAYELSA & 5 & 0 & 0 & 0 & 0 & 0 & 5 & 7 \\
\hline IMO & 3 & 0 & 1 & 0 & 0 & 0 & 2 & 1 \\
\hline ABIA & 2 & 0 & 1 & 0 & 0 & 0 & 1 & 7 \\
\hline BENUE & 2 & 0 & 0 & 0 & 0 & 0 & 2 & 5 \\
\hline ANAMBRA & 1 & 0 & 1 & 0 & 0 & 0 & 0 & 42 \\
\hline TOTAL & 4151 & 239 & 745 & 66 & 128 & 11 & 3278 & \\
\hline
\end{tabular}


rate of community transmission in the State, the team reported that $80 \%$ of samples taken from the State for testing always come out positive

(theeditor@punchng.com). Over 700 deaths have been recorded in that state due to what was termed mysterious diseases. However, the presidential task force on COVID-19 attributed those deaths to the coronavirus pandemic, except for few cases that were as a result of hypertension, meningitis and other disease conditions. Although, as the time of the purported mysterious deaths in Kano State, COVID-19 screening has not commenced in the State, hence these deaths were not on the record of NCDC.

\section{Challenges, Myths and Intrigues of COVID-19 in Nigeria}

Some of the challenges in Nigeria at the onset of the pandemic were the problem of contact tracing due to false or wrong contact addresses given by people who came in from Europe and other parts of the world. There were also handful of COVID-19 patients who ran away from isolation centres in States like Delta, Oyo, Sokoto and Kano. This further puts the State COVID-19 taskforce to commence and intensify contact tracing and immediate decontamination (Punch news, May 5, 2020) [44].

The fallacy by most Nigerians that COVID-19 was strictly associated with the rich $a b$ initio and that, it was brought in from Europe, America, UK etc. by the privileged people and politicians remain a challenge in the community spread of the disease. The limited knowledge of the transmission of coronavirus disease among the general remains a huge challenge. Furthermore, the distrust of Nigeria citizens towards the government was another factor responsible for the increase in the community spread of COVID-19. Another school of thought was that the COVID-19 pandemic was a "phony", as most Nigerians assume it is another avenue for the politicians to embezzle public fund or the tax payer's money. The protest stage by confirmed COVID-19 patient to the street at the Kwadon isolation Centre in Gombe State over abandonment by the government of the State with no medical personnel, no treatment facilities and a poor meal has been identified as another setback for curtailing community spread. Unfortunately, other people living within the environment that were not part of the isolated COVID-19 patients joined in solidarity protest. The protesters were not using face mask, the social distance warning was not observed and some engaged in sharing of used face masks, resulting in increasing risk of COVID-19 spread. Nigeria being a secular nation with multi-regions settings, the closure of places of worship to curtail the spread of COVID-19 was seen by religion organizations as means of depriving them of their freedom of worship. This was flagrant violation of government order on social or physical distancing. Some Northern Nigerian Muslims' faithful went on rampage, when the Law enforcement agency disrupted their Jumat (Friday) service. In another development, there was a serious misconception by some Christian folks that COVID-19 is genetically engineered to drive in the Anti-Christ. Some are of the opinion that the pandemic will ena- 
ble the agents of Anti-Christ to produce vaccine that contain microchips. These chips will serve as a means of identity (mark of the beast in the book of revelation) and at a later date will be used for buying and selling. This microchip was also tied to the current $5 \mathrm{G}$ network (been promoted across the world by Huawei Technology, China), as the required network for the function of the microchips that will be incorporated into the vaccine.

The refusal of government to go against the ethics of medical profession by not showing on National television, people diagnosed with COVID-19 or those evacuated or shown in their isolation wards during treatment prior their recovery and discharged from the hospital, as seen from footages or videos in electronic and social media from other countries around the globe, arose disbelieve of many Nigerians about the true incidence of the COVID-19 in Nigeria, except the Nigeria Centre for Disease Control (NCDC) figures that are been announced daily.

The fears of most Nigerians as regards the actual figure of the COVID-19 positive cases as announced by the NCDC was a typical example of the drama played by the incidence in Dar es Salaam, Tanzania as reported by Voice of America (VOA). In that country, the Coronavirus test kits used were described as faulty by President John Magufuli on $2^{\text {nd }}$ of May, 2020, this was because positive results were said to have returned from Tanzania's laboratory test, on random samples taken from several non-human samples, including samples from pawpaw, goat and sheep that were deliberately assigned human names and ages with unknown origin. As the news from Tanzania ravaged the entire social media, this scenario further added to the misconceptions of some Nigerians that the news of the COVID-19 remains a fierce.

\section{Control Measures on COVID-19 Pandemic}

\subsection{Some Identified Immediate Measures Put in Place by Government on COVID-19 Pandemic}

The government, cooperate bodies, philanthropist have been supportive in the fight against convid-19 transmission via telecast, jingles, adverts, billboards, fliers, poster across Nigeria. The Federal Ministry of Health and the Nigerian Centre for Disease Control worked assiduously to put in place some certain control measures and rules (guidelines) for prevention of COVID-19. These measures include:

1) Washing of hands with soap and running tap water for at least 20 seconds after being in a public place or frequently clean hands by using alcohol-based hand rub;

2) If soap and water are not immediately available, use an alcohol-base hand sanitizer that contains at least $60 \%-70 \%$ alcohol;

3) Use $10 \mathrm{ml}$ of Dettol plus $1 \mathrm{ml}$ of sodium hypochlorite (bleach) in $100 \mathrm{ml}$ of clean water to decontaminate surfaces;

4) Avoid touching, nose, eyes and mouth with unwashed hands; 
5) Avoid close contact with anyone who has a fever and cough or who is sick;

6) Put distance (2-meter gap) between oneself and others as community transmission is fast.

\subsection{Further Instituted Preventive Measures at the Ease of Lockdown in the Affected States Effective $4^{\text {th }}$ of May 2020}

These measures are also applicable nationwide to individuals as well as businesses, employers and employees as follow:

1) Mandatory use of non-medical face mask/covering for all persons.

2) Overnight curfew from 8 p.m. to 6 a.m. This means all movements will be prohibited during this period except for essential services.

3) Mandatory provision of handwashing facilities/sanitizers.

4) Single use latex gloves are discouraged, except in clinical settings, or if used, they should be disposed of safely after each single use.

5) Restrictions on interstate travel except for essential services or transportation of agricultural produce and other essential goods.

6) Extensive temperature checks on entry into the business premises and other public places.

7) Physical distancing of 2 Meters between people in workplaces and other public places.

8) No large gatherings of more than 20 people outside the workplace [45].

\subsection{Scale-Up Actions to Curtail the Current Pandemic and Future Health Related Matters}

The NCDC should not relent on the current efforts as Nigeria is yet to reach the plateau of this disease. Few weeks back, the epicentre of the disease was China in Asia, which later moved to Italy in Europe to USA in North America and now in Brazil in South America. Africa may not escape being an epicentre and Nigeria may be a likely epicentre country in this continent. Therefore, while we await the COVID-19 vaccine which is on pipeline at global level, enforcement of COVID-19 regulations and restriction orders such as regular hand-washing with soap, use of sanitizer, maintenance of physical distancing (3 feet), wearing of facemask and avoidance of large congregation is utmost importance. There is a need for Government to adequately increase budgetary allocation to health and education sectors, to enhance capacity development and innovative research on COVID-19 and other neglected tropical diseases. The current presentation of COVID-19 syndrome with community acquired pneumonia symptoms, calls for inward research into historical perspective of bacterial superinfection in influenza, where co-infection or secondary bacterial pneumonia in $11 \%-35 \%$ of hospitalized patients had been documented [46] [47] SARS-COV-2 co-infections with other respiratory pathogens may further give an insight into COVID-19 complications in patients. This may pave the way for promoting appropriate antimicrobial prescription and use, during COVID-19 pandemic and beyond. It may also to 
guide against the widespread use of antibiotics and higher rate of microbial resistance.

Effective people's health preventive behavior is essential in order to curtail COVID-19 spread in Nigeria. This could be achieved through a scale-up awareness by involving, community leaders, traditional rulers, religious leaders, union or association leaders, professional associations, civil society leaders in the enlightenment campaign to stem community transmission of COVID-19 and to disabuse the minds of the ordinary people who are being made to believe that COVID-19 is not real or it is a disease of the rich. There must be consciousness that the disease has no social or economic barrier, as it cuts across all age groups, gender, trade, social or economic status.

The current National Health Insurance Scheme seems not to be achieving the purpose for which it was formulated. This policy is believed to be meant for workers in the public service and private organizations, of which many workers could not afford. Besides, the workers in the informal sector such as artisans, farmers etc, are not accommodated in the scheme. Furthermore, in 2015, Lagos State Government formulated Health Insurance Policy Scheme for her citizens, this policy should be implemented without further delay to ease the burden of Lagosians on health-related issues and serve as a catalyst for other states to emulate. Government at all levels should embark on community-based health policy that will bring health services to the door-step of every citizen through a reliable, flexible, subsidized and affordable health insurance policy.

\section{Conclusion}

Coronavirus disease (COVID-19) has risen considerably in Nigeria and is expected to rise in the coming weeks and months with unpredictable plateau. Lagos State remains the epicentre of the disease. The change in disease dynamics may be witnessed in some northern states of Nigeria due to flagrant violation of NCDC guidelines. Lack of both human and material recourses have been a serious setback in the containment of the disease. Inadequate Molecular laboratories and diagnostic facility to carry out concurrent tests across the country might have necessitated increasing community transmission. Lack of political will to invest on health sector by the successive governments in Nigeria has contributed to the present predicament in the management of COVID-19 pandemic. Poor socio-political and economic status of Nigeria nation has made poverty, unemployment and insurgency to be on the rise, thus, making it very difficult for citizens to adhere strictly to the government directives and NCDC guidelines. Poor enforcement of on the parts of some state governments is a big issue to contain and stem the spread of this disease. While the issue of the economic downturn bites harder, the government must choose between taking a drastic step to prevent the community spread of COVID-19 or to play to the gallery of economic downturn. The government as a matter of urgency needs to increase their testing capacity, build more isolation centres, prepare for palliatives for its citizen and 
lockdown the entire country for specific number of weeks once for all, if this pandemic must be curtailed on time.

\section{Recommendations}

The following are some recommendations put forward for the response to the COVID-19 pandemic in Nigerian and other countries alike. This includes:

1) The need for Presidential task force on COVID-19 to intensify efforts to review data and emerging evidence and make the outcomes available to the community and religious leaders.

2) The health workers, security personnel's and other essential workers must be respected and protected.

3) The special population at risk and vulnerable groups, such as children, elderly and women must be monitored and protected.

4) Federal Ministry of Health in Conjunction with NCDC should engage more hands to make use a call center to coordinate the public health response and provide clinical and social support to people with symptoms of COVID-19.

5) Government should scale-up molecular laboratories and diagnostic centres for COVID-19 test.

6) NCDC should intensify efforts on testing isolation, contact tracing, quarantine, symptom tracking and supportive services across the 36 states of the federation and FCT, Abuja.

7) There is a need to establish community-based testing sites and granting approval and capacity to conduct COVID-19 test to some well-equipped private hospitals with Biosafety level 2 for a start and/or 3 as standard.

8) There should be proper documentation and provision of social services to people in isolation and quarantine and people adversely affected by community measures in order to contain the spread of COVID-19.

9) There is a need for aggressive public enlightenment campaign and daily delivery of comprehensive, informative messages to the public on symptoms, spread and control of COVID-19.

10) The use data to inform and update the response strategy is equally essential.

11) Continuous education of the citizens on the danger involved in sharing and wearing of used face mask.

12) Government should as a matter of urgency come up with public giggles to prevent and discourage stigmatization of COVID-19 positive individuals.

13) A need to evolve national policy on innovative research and capacity building in line with global best practices, particularly in the areas of surveillance, diagnosis and interventions for COVID-19 and other neglected tropical diseases should be of a great priority.

\section{Conflicts of Interest}

The authors declare no conflicts of interest regarding the publication of this paper. 


\section{References}

[1] European Centre for Disease Prevention and Control (2020) Disease Background of COVID-19: Rapid Risk Assessment: Coronavirus Disease 2019 (COVID-19) in the EU/EEA and the UK-Ninth Update.

[2] WMHC (2020) Wuhan Municipal Health and Health Commission's Briefing on the Current Pneumonia Epidemic Situation in Our City.

https://idpjournal.biomedcentral.com/articles/10.1186/s40249-020-00646-x

[3] Johns Hopkins Coronavirus Resource Center (2020) https://coronavirus.jhu.edu/data/cumulative-cases

[4] Adhikari, S.P., Meng, S., Wu, Y.-J., Mao, Y.-P., Ye, R.-X., Wang, Q.-Z., Sun, C., Sylvia, S., Rozelle, S., Raat, H. and Zhou, H. (2020) Epidemiology, Causes, Clinical Manifestation and Diagnosis, Prevention and Control of Coronavirus Disease (COVID-19) during the Early Outbreak Period: A Scoping Review. Infectious Diseases of Poverty, 9, Article No. 29.

https://idpjournal.biomedcentral.com/track/pdf/10.1186/s40249-020-00646-x https://doi.org/10.1186/s40249-020-00646-x

[5] WHO (2020) Novel Coronavirus-China. https://www.who.int/csr/don/12-january-2020-novel-coronavirus-china/en/

[6] CDC (2020) 2019 Novel Coronavirus, Wuhan, China. https://www.cdc.gov/coronavirus/2019-nCoV/summary.html

[7] Mcleod, V. (2020) COVID-19: A History of Coronavirus. Lab Health and Safety.

[8] Zhu, N., Zhang, D.Y., Wang, W.L., Li, X.W., Yang, B., Song, J.D., et al. (2020) A Novel Coronavirus from Patients with Pneumonia in China, 2019. The New England Journal of Medicine, 382, 727-733. https://doi.org/10.1056/NEJMoa2001017

[9] WHO (2020) Novel Coronavirus-Japan (ex-China). https://www.who.int/csr/don/17-january-2020-novel-coronavirus-japan-ex-china/e $\underline{\mathrm{n} /}$

[10] Virological (2020) Novel 2019 Coronavirus Genome. https://virological.org/t/novel-2019-coronavirus-genome/319

[11] John Hopkins University (2020) The Role of Genomic Sequencing in Combating COVID-19: COVID-19 Information and Resource for John Hopkin University.

[12] Fehr, A.R., Channappanavar, R. and Perlman, S. (2017) Middle East Respiratory Syndrome: Emergence of a Pathogenic Human Coronavirus. Annual Review of Medicine, 68, 387-399. https://doi.org/10.1146/annurev-med-051215-031152

[13] WHO (2020) Statement on the Second Meeting of the International Health Regulations (2005) Emergency Committee Regarding the Outbreak of Novel Coronavirus (2019-nCoV) 2020.

https://www.who.int/news-room/detail/30-01-2020-statement-on-the-second-meeti ng-of-the-international-health-regulations-(2005)-emergency-committee-regarding -the-outbreak-of-novel-coronavirus-(2019-ncov)

[14] Sah, R., Rodriguez-Morales, A.J., Jha. R., Chu, D.K.W., Gu. H., Peiris, M., Bastola, A., Lal, B.K., Ojha, H.C., Rabaan, A.A., Zambrano, L.I., Costello, A., Morita, K., Pandey, B.D. and Poon, L.L.M. (2020) Complete Genome Sequence of a 2019 Novel Coronavirus (SARS-CoV-2) Strain Isolated in Nepal. Microbiology Resource Announcements, 9, e00169-20. https://doi.org/10.1128/MRA.00169-20

[15] Huang, C., Wang, Y., Li, X., Ren. L., Zhao, J., Hu, Y., Zhang, L., Fan, G., Xu, J., Gu, X., Cheng, Z., Yu, T., Xia, J., Wei, Y., Wu, W., Xie, X., Yin, W., Li, H., Liu. M., Xiao, Y., Gao, H., Guo, L., Xie, J., Wang, G., Jiang, R., Gao, Z., Jin, Q., Wang, J. and Cao, 
B. (2020) Clinical Features of Patients Infected with 2019 Novel Coronavirus in Wuhan, China. Lancet, 395, 497-506. https://doi.org/10.1016/S0140-6736(20)30183-5

[16] Kumar, D., Malviya, R. and Sharma, K.P. (2020) Corona Virus: A Review of COVID-19. EJMO, 4, 8-25. https://doi.org/10.14744/ejmo.2020.51418

[17] Wang, W., Xu, Y.L., Gao, R.R., et al. (2020) Detection of SARS-CoV-2 in Different Types of Clinical Specimens. JAMA, 323, 1843-1844. https://doi.org/10.1001/jama.2020.3786

[18] WHO (2020) Coronavirus Disease 2019 (COVID-19). Situation Report-73.

[19] Li, Q., Guan, X., Wu, P., Wang, X., Zhou, L., Tong, Y., et al. (2020) Early Transmission Dynamics in Wuhan, China, of Novel Coronavirus-Infected Pneumonia. New England Journal of Medicine, 382, 1199-1207.

[20] National Health Commission of People's Republic of China (2020) Prevent Guideline of 2019-nCoV. http://www.nhc.gov.cn/xcs/yqfkdt/202001/bc661e49b5bc487dba182f5c49ac445b.sht $\underline{\mathrm{ml}}$

[21] Su, S., Wong, G., Shi, W., Liu, J., Lai, A.C.K., Zhou, J., Liu, W.J., Bi, Y.H. and Gao, G.F. (2016) Epidemiology, Genetic Recombination, and Pathogenesis of Coronaviruses. Trend in Microbiology, 24, 490-502. https://doi.org/10.1016/j.tim.2016.03.003

[22] Chen, Y., Liu, Q. and Guo, D. (2020) Coronaviruses: Genome Structure, Replication, and Pathogenesis. Journal of Medical Virology, 92, 418-423. https://doi.org/10.1002/jmv.25681

[23] Carvalho, T. (2020) COVID-19 Research in Brief. Nature Medicine.

[24] Ren, L.L., Wang, Y.M., Wu, Z.Q., Xiang, Z.C., Guo, L., Xu, T., Jiang, Y.Z., Xiong, Y., Li, Y.J., Li, X.W., Li, H., Fan, G.H., Gu, X. Y., Xiao, Y., Gao, H., Xu, J.Y., Yang, F., Wang, X.M., Wu, C., Chen, L., Liu, Y.W., Liu, B., Yang, J., Wang, X.R., Dong, J., Li, L., Huang, C.L., Zhao, J.P., Hu, Y., Cheng, Z.S., Liu, L.L., Qian, Z.H., Qin, C., Jin, Q., Cao, B. and Wang, J.W. (2020) Identification of a Novel Coronavirus Causing Severe Pneumonia in Human: A Descriptive Study. Chinese Medical Journal, 133, 1015-1024.

[25] Roujian, L., Zhao, X., Li, J., Niu, P., Yang, B., Wu, H., et al. (2020) Genomic Characterisation and Epidemiology of 2019 Novel Coronavirus: Implications for Virus Origins and Receptor Binding. Lancet, 395, 565-574.

[26] Vaduganathan, M., Vardeny, O., Michel, T., McMurray, J.J.V., Marc, A., Solomon, S.D., et al. (2020) Renin-Angiotensin-Aldosterone System Inhibitors in Patients with Covid-19. New England Journal of Medicine, 382, 1653-1659. https://doi.org/10.1056/NEJMsr2005760

[27] Zhou, P., Yang, X.L., Wang, X.G., Hu, B., Zhang, L., Zhang, W., et al. (2020) Discovery of a Novel Coronavirus Associated with the Recent Pneumonia Outbreak in Humans and Its Potential Bat Origin. bioRxiv.

https://doi.org/10.1101/2020.01.22.914952

[28] Li, W., Zhang, C., Sui, J., et al. (2005) Receptor and Viral Determinants of SARSCoronavirus Adaptation to Human ACE2. The EMBO Journal, 24, 1634-1643. https://doi.org/10.1038/sj.emboj.7600640

[29] Wrapp, D., Wang, N., Corbett, K.S., et al. (2020) Cryo-EM Structure of the 2019nCoV Spike in the Prefusion Conformation. Science, 376, 1260-1263.

https://doi.org/10.1126/science.abb2507 
[30] Angeletti, S., Benvenuto, D., Bianchi, M., Giovanetti, M., Pascarella, S. and Ciccozzi, M. (2020) COVID-2019: The Role of the nsp2 and nsp3 in Its Pathogenesis. Journal of Medical Virology, 92, 584-588. https://doi.org/10.1002/jmv.25719

[31] Li, D., Jin, M., Bao, P., Zhao, W. and Zhang, S. (2020) Clinical Characteristics and Results of Semen Test among Men with Coronavirus Disease. JAMA Network Open, 3, e208292. https://doi.org/10.1001/jamanetworkopen.2020.8292

[32] Liu, J., Liao, X., Qian, S., et al. (2020) Community Transmission of Severe Acute Respiratory Syndrome Coronavirus 2, Shenzhen, China, 2020. Emerging Infectious Diseases, 26, 1320-1323. https://doi.org/10.3201/eid2606.200239

[33] Chan, J., Yuan, S., Kok, K. et al. (2020) A Familial Cluster of Pneumonia Associated with the 2019 Novel Coronavirus Indicating Person-to-Person Transmission: A Study of a Family Cluster. Lancet, 395, 514-523. https://doi.org/10.1016/S0140-6736(20)30154-9

[34] Lauer, S.A., Grantz, K.H., Bi, Q., et al. (2020) The Incubation Period of Coronavirus Disease 2019 (COVID-19) from Publicly Reported Confirmed Cases: Estimation and Application. Annals Internal Medicine. https://doi.org/10.7326/M20-0504

[35] Wolfel, R., Corman, V., Guggemos, W., et al. (2020) Virological Assessment of Hospitalized Cases of Coronavirus Disease.

[36] Yu, P., Zhu, J., Zhang, Z. and Han, Y. (2020) A Familial Cluster of Infection Associated with the 2019 Novel Coronavirus Indicating Possible Person-to-Person Transmission during the Incubation Period. The Journal of Infectious Diseases, 221, 1757-1761. https://doi.org/10.1093/infdis/jiaa077

[37] Pan, X., Chen, D., Xia, Y., et al. (2020) Asymptomatic Cases in a Family Cluster with SARS-CoV-2 Infection. The Lancet Infectious Diseases, 20, 410-411. https://doi.org/10.1016/S1473-3099(20)30114-6

[38] European Centre for Disease Prevention and Control (2020) Situation Update Worldwide, as of 30 April 2020.

https://www.ecdc.europa.eu/en/publications-data/download-todays-data-geographi c-distribution-covid-19-cases-worldwide

[39] Ruth, M. (2020) Africa Braces for Coronavirus but Slowly, the New York Times.

[40] Abdulazeez, A. (2020) More Preparedness on Coronavirus Disease-2019 (COVID-19) in Nigeria. Pan African Journal of Life Sciences, 4, 200-203.

[41] World Health Organization Regional Office Africa (2020) COVID-19 WHO Africa Update 30 April, 2020.

[42] NCDC (2020) COVID-19 Outbreak in Nigeria Situation Report.

[43] NCDC (2020) COVID-19 Situation Report Situation Report 24.

[44] NCDC (2020) COVID-19 Situation Report Situation Report 71.

[45] NCDC (2020) Guideline for Employers and Businesses in Nigeria.

[46] Huttner, B.D., Catho, G., Pano-Pardo, J.R., Pulcini, C. and Schouten, J. (2020) COVID-19: Don't Neglect Antimicrobial Stewardship Principles! Clinical Microbiology and Infection, 26, 808-810.

[47] Antimicrobial Stewardship during COVID-19. https://aimed.net.au/2020/06/11/antimicrobial-stewardship-during-covid-19/ 